\title{
CORRECTION
}

\section{Correction to: A comprehensive review on radioactive waste cycle from generation to disposal}

\author{
Sharif Abu Darda ${ }^{1} \cdot$ Hossam A. Gabbar ${ }^{1,2}$ (1) $\cdot$ Vahid Damideh $^{1} \cdot$ Mohamed Aboughaly $^{1} \cdot$ Isaac Hassen $^{1}$
}

Published online: 9 June 2021

๑) Akadémiai Kiadó, Budapest, Hungary 2021

\section{Correction to: J Radioanal Nucl Chem} https://doi.org/10.1007/s10967-021-07764-2

In the original publication of the article, fourth author's name was misspelt. The correct name is given in this correction.

The original article has been corrected.

Publisher's Note Springer Nature remains neutral with regard to jurisdictional claims in published maps and institutional affiliations.

The original article can be found online at https://doi.org/10.1007/ s10967-021-07764-2.

Hossam A. Gabbar

hossam.gabbar@uoit.ca

1 Faculty of Energy Systems and Nuclear Science, Ontario Tech University, Oshawa, Canada

2 Faculty of Engineering and Applied Science, Ontario Tech University, Oshawa, Canada 